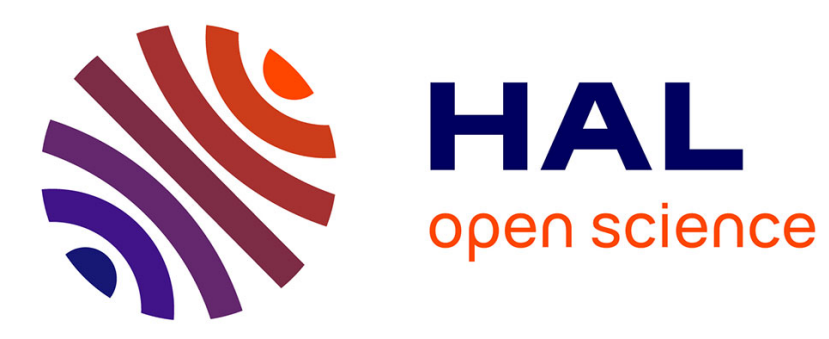

\title{
Pulmonary arterial hypertension in four patients treated by leflunomide
}

Valentin Coirier, Alain Lescoat, Celine Chabanne, Maxime Fournet, Guillaume Coiffier, Stéphane Jouneau, Elisabeth Polard, Patrick Jego

\section{> To cite this version:}

Valentin Coirier, Alain Lescoat, Celine Chabanne, Maxime Fournet, Guillaume Coiffier, et al.. Pulmonary arterial hypertension in four patients treated by leflunomide. Joint Bone Spine, 2018, 85 (6), pp.761-763. 10.1016/j.jbspin.2017.12.014 . hal-01863795

\section{HAL Id: hal-01863795}

\section{https://hal-univ-rennes1.archives-ouvertes.fr/hal-01863795}

Submitted on 29 Aug 2018

HAL is a multi-disciplinary open access archive for the deposit and dissemination of scientific research documents, whether they are published or not. The documents may come from teaching and research institutions in France or abroad, or from public or private research centers.
L'archive ouverte pluridisciplinaire HAL, est destinée au dépôt et à la diffusion de documents scientifiques de niveau recherche, publiés ou non, émanant des établissements d'enseignement et de recherche français ou étrangers, des laboratoires publics ou privés. 


\section{Pulmonary Arterial Hypertension in four patients treated by leflunomide.}

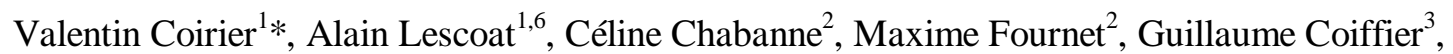
Stéphane Jouneau ${ }^{4,6}$, Elisabeth Polard ${ }^{5}$, Patrick Jégo ${ }^{1,6}$

${ }^{1}$ Department of Internal Medicine, Rennes University Hospital, 35203 Rennes, France

${ }^{2}$ Department of Cardiology, Rennes University Hospital, 35203 Rennes, France

${ }^{3}$ Department of Rheumatology, Rennes University Hospital, 35203 Rennes, France

${ }^{4}$ Department of Pneumology, Rennes University Hospital, 35203 Rennes, France

${ }^{5}$ Department of Pharmacovigilance, Rennes University Hospital, 35203 Rennes, France

${ }^{6}$ UMR INSERM U1085, Research Institute in Health, Environment and Occupation / Institut de Recherche sur la Santé, l'Environnement et le Travail (IRSET), Universisty of Rennes 1, 35203 Rennes, France

* Corresponding author: Valentin Coirier

Department of Internal Medicine, Rennes University Hospital, South Hospital, 16 bd de Bulgarie 35203 Rennes cedex 2 - BP 90347, France

E-Mail : valentin.coirier@gmail.com

Phone: +33299267128 fax: +33299267198 


\section{$\underline{\text { Abstract }}$}

Pulmonary arterial hypertension (PAH) is a rare disorder that can be drug-induced, mostly following treatment by appetite-suppressant drugs. We report four cases of patients who developed PAH following a treatment by leflunomide for rheumatoid arthritis, psoriatic arthritis or undetermined connective tissue disease. All patients described a progressive dyspnea from grade II to IV of NYHA classification; clinical examination found signs of heart failure. PAH was finally diagnosed and confirmed by right heart catheterisation. Haemodynamic explorations found pre-capillary pulmonary hypertension with mean pulmonary arterial pressure above $25 \mathrm{mmHg}$, and pulmonary capillary wedge pressure under $15 \mathrm{mmHg}$. Explorations of this pre-capillary pulmonary hypertension were conducted according to international guidelines: pulmonary or chronic thromboembolic aetiologies were excluded after ventilation/perfusion lung scan and high-resolution computed tomography. All other etiologic explorations were negative. Imputability of leflunomide was finally retained. Leflunomide was stopped for all patients; three of them received specific PAH treatments. A favourable clinical and/or haemodynamic evolution was observed for all patients. The conclusions of the investigations conducted by our pharmacovigilance centre were communicated to the European Medicines Agency, leading to the addition of "pulmonary hypertension" in the paragraph "special warning and precautions of use" of the package leaflet of leflunomide.

\section{$\underline{\text { Key words }}$}

Leflunomide. Pulmonary Arterial Hypertension. 


\section{Introduction}

Pulmonary arterial hypertension $(\mathrm{PAH})$ is a rare disorder. $\mathrm{PAH}$ diagnosis is based on right heart catheterisation (RHC) [1], showing a mean pulmonary arterial pressure (mPAP) above $25 \mathrm{mmHg}$, associated with pulmonary capillary wedge pressure (PCWP) under $15 \mathrm{mmHg}$, in favour of pre-capillary pulmonary hypertension $(\mathrm{PH})$. To confirm $\mathrm{PAH}$, other aetiologies of pre-capillary PH (groups III and IV of the PH classification [1]) must be excluded: PH due to lung disease or hypoxia (mainly chronic obstructive pulmonary disease and interstitial lung disease (ILD)) and chronic thromboembolic PH. PAH is confirmed after exclusion of these differential diagnoses (normal ventilation/perfusion lung scan and normal high-resolution computed tomography), and the next step

is to perform aetiological investigations to determine the proper aetiological diagnosis allowing a specific treatment. PH of group I, corresponds to PAH [Appendix A, Table S1; See the supplementary material associated with this article online] and includes idiopathic PAH, heritable $\mathrm{PAH}$, drugs and toxins induced $\mathrm{PAH}, \mathrm{PAH}$ associated with connective tissue diseases (CTD), human immunodeficiency virus (HIV) infection, portal hypertension and congenital heart diseases.

In the 1960s, an epidemic of PAH in European women taking appetite-suppressant drugs [2] led to an improvement of PAH diagnosis and additional drugs increasing the risk of PAH were identified. In 2013, Montani et al. [3] published a review identifying anorexigen drugs (aminorex, fenfluramine and derivatives, benfluorex, amphetamines), dasatinib, interferon alpha and beta as risk factors of drug-induced PAH.

Leflunomide is a selective inhibitor of de novo pyrimidine synthesis [4], prescribed for rheumatoid arthritis (RA) and psoriatic arthritis (PA). We report four cases of PAH following treatment by leflunomide.

\section{Case-reports}

The four patients were aged from 51 to 71 years-old at the time of the diagnosis of PAH (Table I). One patient received leflunomide $10 \mathrm{mg}$ per day, the three others received $20 \mathrm{mg}$ per day. Delay between leflunomide initiation and first symptoms of PAH ranged from 7 to 120 months. Two patients received leflunomide for RA, one for PA. The fourth patient was 
treated by leflunomide for an undetermined CTD (insufficient diagnostic criteria for systemic sclerosis or systemic lupus erythematosus) with disabling arthralgia, a questionable indication for leflunomide.

The four patients initially consulted for a recent dyspnea. At diagnosis, the dyspnea was estimated from grade II to IV using New York Heart Association (NYHA) functional grading. After clinical examination, a cardiac aetiology of the dyspnea was suspected leading to transthoracic echocardiographic (TTE) evaluation. TTE found an increased estimated systolic pulmonary arterial pressure for all of them. PH was then confirmed by RHC (Table I) for all patients (mPAP between 35 and $48 \mathrm{mmHg}$ ), with haemodynamic profiles of pre-capillary $\mathrm{PH}$ (PCWP between 5 and $14 \mathrm{mmHg}$ ). Pulmonary vascular resistances (PVR) were increased and cardiac output (CO) decreased in all patients.

All patients underwent classical investigations for pre-capillary $\mathrm{PH}$ : biological evaluation for auto-immune disease, HIV serology, abdominal ultrasound scan, ventilation/perfusion lung scan and lung high-resolution computed tomography (CT). For patients 2 and 4, lung CT showed an aspect of ILD that was already known before initiation of leflunomide. ILD did not evolve on the new CT scan in comparison with the CT scan prior to leflunomide initiation. Therefore PAH could not be secondary to the evolution of ILD. Other investigations for these two patients were negative. All investigations for patients 1 and 3 were also negative. For each patient, a pharmacovigilance reporting (declarations numbers RS20141210, RS20150927, RS20150576, RS20172152) was performed at the Rennes University Hospital pharmacovigilance centre, that conducted accountability investigations.

Leflunomide treatment was immediately stopped for two patients, five months after diagnosis for another and three years after diagnosis for the last one. Patients 1, 3 and 4 underwent specific PAH treatment. Patient 2 did not receive any PAH treatment. As recommended in case of serious adverse event, a wash-out procedure using cholestyramine was performed in patients 1 and 2 ( $8 \mathrm{~g}$ three times a day, during 11 days); physicians in charge of patients 3 and 4 did not prescribe cholestyramine. Treatment strategy was determined during a multidisciplinary concertation, according to the ESC/ERS guidelines and adapted to the severity of PAH for each patient.

Evolution was evaluated according to the functional and haemodynamic parameters (Table II). Improvement was observed at the first follow-up visit after discontinuation of the treatment (between two and four months). For all patients, clinical or haemodynamic evolution was favourable. 


\section{Discussion}

We report four cases of PAH following treatment by leflunomide. Evolution (clinical, echocardiographic and/or haemodynamic) was favourable for all patients after discontinuation of leflunomide (without specific PAH treatment, for one patient) or introduction of a specific treatment for PAH.

Confirming the link between PAH and drug intake remains a great challenge, because PAH is always a rare complication occurring only in a very small proportion of exposed patients. Furthermore, in our four cases, re-administration of leflunomide was not possible, because of the serious adverse effect reported. We concluded to the diagnosis of PAH because precapillary PH was confirmed by RHC for all of them and there was no evidence for a PH group III aetiology: complementary explorations found neither worsening (patients 2 and 4) of an already known respiratory disease nor any argument for chronic thromboembolic disease. We then concluded to the diagnosis of drug-induced PAH after careful elimination of other aetiologies: before initiation of leflunomide, no patient had previous treatment at risk of druginduced PAH. No HIV infection was found, no cirrhotic or congenital heart disease was diagnosed. Heritable mutations were not investigated but a careful anamnesis ruled out any familial history of PAH. Imputability assessment methods for adverse drug reactions established the level of causality as possible (Naranjo [5] and OMS algorithms) or plausible (French method). Haemodynamic improvement after treatment discontinuation, without introduction of PAH treatment in patient 2, is a strong evidence in favour of leflunomideinduced PAH. In 2012 Alvarez et al. [6], reported one case of PAH in a 28-year-old patient treated by leflunomide for RA. RHC was performed to confirm diagnosis, aetiological explorations were negative, evolution was favourable after leflunomide discontinuation and introduction of a specific PAH treatment (sildenafil, bosentan and acenocoumarol). Another case was published in 2004 by Martinez-Taboada et al. [7], reporting a 70-year-old patient also treated by leflunomide for RA. Diagnosis was not confirmed by haemodynamic explorations, but echocardiographic evolution was also favourable after discontinuation of leflunomide.

The conclusions of the investigations conducted by our pharmacovigilance centre were communicated to the European Medicines Agency, leading to the addition of "pulmonary hypertension" in the paragraph "special warnings and precautions for use" and "undesirable effects" of the package leaflet of leflunomide. The report of other cases will strengthen this hypothesis of leflunomide associated PAH. 
If the role of leflunomide in the development of PAH were confirmed, the question of its involvement in the pathophysiology of a specific pulmonary vascular disease would arise. For other PAH inducing drugs, pathophysiology hypotheses have been suggested: inhibition of serotonin reuptake for fenfluramine and derivatives, ability to inhibit tyrosine kinase activity for dasatinib. Dasatinib might specifically inhibit a sub-family of kinases, named Src kinase, which would explain the specific effect of dasatinib and the absence of a class effect [8]. This hypothesis is supported by several studies demonstrating the role of Src tyrosine kinases in maintaining the integrity of the pulmonary vascular bed [9]. In 2013, Nagaraj et al. [10] reported the co-localization of Src and TASK-1 (potassium channel) in the plasma membrane of human pulmonary arterial smooth muscle cells (hPASMCs). TASK-1 plays a role in the resting membrane potential of hPASMCs, therefore participating in the regulation of the pulmonary artery vascular tone. Nagarajet al. demonstrated that specific inhibition of Src results in the inhibition of TASK-1 (and others potassium channels), plasma membrane depolarization and hPASMCs contraction. The author concluded that Src tyrosine kinases control potassium channels (including TASK-1), which explains why their inhibition can lead to pulmonary vasoconstriction. Similarly, in vitro studies have also reported an inhibiting effect of leflunomide on this family of Src tyrosine kinases. These elements remain hypothetic and both the involvement and precise role of Src-kinases in the pathogenesis of leflunomideassociated PAH are still to be determined.

Leflunomide is a prodrug rapidly converted in the gastrointestinal tract and plasma in its metabolite [4], A77 1726. This metabolite inhibits de novo synthesis of pyrimidine ribonucleotides, regulating lymphocytes proliferation with an immunomodulatory effect. A77 1726 also named teriflunomide, has been recently authorised in the treatment of multiple sclerosis (relapsing-remitting form). Some of the classical adverse effects associated with leflunomide are also described with teriflunomide: systemic hypertension, hepatic cytolysis, cytopenia, peripheral neuropathy and alopecia. If the imputability of leflunomide in the development of PAH were confirmed, prescribers of teriflunomide should be attentive to the occurrence of PAH under treatment. Even if the accurate quantification of leflunomide prescriptions seems difficult to evaluate, the use of teriflunomide will significantly increase the number of patients exposed to A77 1726. For example, the French Authority of Health estimated in 2012 that 50000 patients could benefit from a prescription of teriflunomide, in the treatment of multiple sclerosis [11]. Further observational studies and pharmacovigilance investigations are therefore needed to assess the risk of PAH in patients treated by teriflunomide in the future. 
Page 7 of 11 


\section{Disclosure of interest}

The authors report no conflicts of interest related to the article.

\section{Appendix A. Supplementary data}

Supplementary data (Table S1) associated with this article can be found in the online version at $\ldots$ 


\section{References}

[1] Galiè N, Humbert M, Vachiery JL, et al. 2015 ESC/ERS Guidelines for the diagnosis and treatment of pulmonary hypertension. Eur Heart J. 2016;37(1):67-119.

[2] Abenhaim L, Moride Y, Brenot F, et al. Appetite-suppressant drugs and the risk of primary pulmonary hypertension. N Engl J Med. 1996;335(9):609-16.

[3] Montani D, Seferian A, Savale L, et al. Drug-induced pulmonary arterial hypertension: a recent outbreak. Eur Respir Rev. 2013;22(129):244-250.

[4] Breedveld FC, Dayer JM. Leflunomide: mode of action in the treatment of rheumatoid arthritis. Ann Rheum Dis. 2000;59(11):841-849.

[5] Naranjo CA, Busto U, Sellers EM, et al. A method for estimating the probability of adverse drug reactions. Clin Pharmacol Ther. 1981;30(2):239-45.

[6] Alvarez PA, Saad AK, Flagel S, et al. Leflunomide-Induced Pulmonary Arterial Hypertension in a Young Woman with Rheumatoid Arthritis: A Case Report. Cardiovasc Toxicol. 2012;12(2):180-183.

[7] Martinez-Taboada VM, Rodriguez-Valverde V, Gonzalez-Vilchez F, et al. Pulmonary hypertension in a patient with rheumatoid arthritis treated with leflunomide. Rheumatology. 2004;43(11):1451-1453.

[8] Montani D, Bergot E, Günther S, et al. Pulmonary Arterial Hypertension in Patients Treated by Dasatinib. Circulation. 2012;125(17):2128-2137.

[9] Pullamsetti SS, Berghausen EM, Dabral S, et al. Role of Src Tyrosine Kinases in Experimental Pulmonary Hypertension. Arterioscler Thromb Vasc Biol. 2012;32(6):13541365.

[10] Nagaraj C, Tang B, Balint Z et al. Src tyrosine kinase is crucial for potassium channel function in human pulmonary arteries. Eur Respir J. 2013;41:85-95.

[11] https://www.has-sante.fr/portail/upload/docs/evamed/CT-13125_AUBAGIO_PIC_INS _Avis3_CT13125.pdf. Accessed 20 October 2017. 
Table I: Characteristics of patients at the moment of $\mathrm{PH}$ diagnosis

\begin{tabular}{ccccccccccc}
\hline & $\begin{array}{c}\text { Age at } \\
\text { diagnosis } \\
\text { (years) }\end{array}$ & $\begin{array}{c}\text { Sex } \\
\text { (M/F) }\end{array}$ & Disease & $\begin{array}{c}\text { Duration of } \\
\text { treatment* } \\
\text { (months) }\end{array}$ & $\begin{array}{c}\text { Dose of } \\
\text { leflunomide, } \\
\text { at diagnosis } \\
\text { (mg/d) }\end{array}$ & $\begin{array}{c}\text { NYHA FC } \\
\text { (I-IV) }\end{array}$ & $\begin{array}{c}\text { mPAP } \\
(\mathbf{m m H g})\end{array}$ & $\begin{array}{c}\text { PCWP } \\
(\mathbf{m m H g})\end{array}$ & $\begin{array}{c}\text { CO } \\
(\mathbf{L} / \mathbf{m i n})\end{array}$ & $\begin{array}{c}\text { PVR } \\
\text { (WU) }\end{array}$ \\
$\mathbf{1}$ & 51 & F & PA & 48 & 20 & IV & 48 & 14 & 4,47 & 7,6 \\
$\mathbf{2}$ & 56 & H & RA & 7 & 20 & II & 38 & 9 & 4,5 & 6,4 \\
$\mathbf{3}$ & 71 & F & RA & 120 & 10 & IV & 43 & 5 & 1,4 & 14,6 \\
$\mathbf{4}$ & 59 & M & uCTD & 46 & 20 & IV & 35 & 8 & 3,77 & 7,1
\end{tabular}

NYHA FC: New-York Hearth Association functional class; mPAP: mean pulmonary arterial pressure; PCW: pulmonary capillary wedge pressure; CO: cardiac output; PVR: pulmonary vascular resistance in Wood Units; PA: psoriatic arthritis; RA: rheumatoid arthritis; uCTD: undetermined connective tissue disease (not systemic sclerosis, not systemic erythematous lupus).

* delay between initiation of leflunomide et diagnosis of pulmonary arterial hypertension. 
Table II: Management of PAH and outcomes (last PAH evaluation)

\begin{tabular}{|c|c|c|c|c|c|c|c|}
\hline & $\begin{array}{c}\text { PAH } \\
\text { treatment }\end{array}$ & $\begin{array}{c}\text { PAH treatment } \\
\text { at last } \\
\text { evaluation* }\end{array}$ & $\begin{array}{c}\text { NYHA } \\
\text { FC } \\
\text { (I-IV) }\end{array}$ & $\begin{array}{c}\text { mPAP } \\
(\mathbf{m m H g})\end{array}$ & $\begin{array}{c}\text { PCWP } \\
\text { (mmHg) }\end{array}$ & $\begin{array}{c}\text { CO } \\
(\mathrm{L} / \mathrm{min})\end{array}$ & $\begin{array}{l}\text { PVR } \\
\text { (WU) }\end{array}$ \\
\hline Patient 1 & $\begin{array}{l}\text { epoprostenol, } \\
\text { bosentan, } \\
\text { treprostinil, } \\
\text { ambrisentan, } \\
\text { sildenafil }\end{array}$ & $\begin{array}{l}\text { ambrisentan, } \\
\text { sildenafil }\end{array}$ & II & 33 & 8 & 7,2 & 3,47 \\
\hline Patient 2 & no treatment & no treatment & II & 31 & 11 & 6,4 & 3,1 \\
\hline Patient 3 & $\begin{array}{l}\text { sildenafil, } \\
\text { bosentan }\end{array}$ & $\begin{array}{l}\text { sildenafil, } \\
\text { bosentan }\end{array}$ & I & 43 & 10 & 5 & \\
\hline Patient 4 & sildenafil & sildenafil & I & 32 & 12 & 9,6 & 2,08 \\
\hline
\end{tabular}

PAH: pulmonary arterial hypertension; NYHA FC: New-York Hearth Association functional class; mPA: mean pulmonary arterial pressure; PCW: pulmonary capillary wedge pressure; CO: cardiac output; PVR: pulmonary vascular resistance in Wood Units.

* last haemodynamic evaluation of the patient before article submission. 